BULLETIN Bulletin hispanique

HISPANIQUE Université Michel de Montaigne Bordeaux

118-1 | 2016

La Guerre Civile espagnole aujourd'hui (1936-2016)

Bernard Sicot, Djelfa 41-43. Un camp d'internement en Algérie (histoire, témoignages, littérature)

Riveneuve, Paris, 2015

Jacques Issorel

\title{
OpenEdition
}

Journals

Édition électronique

URL : http://journals.openedition.org/bulletinhispanique/4450

DOI : 10.4000/bulletinhispanique.4450

ISSN : $1775-3821$

Éditeur

Presses universitaires de Bordeaux

Édition imprimée

Date de publication : 15 juillet 2016

Pagination : 389-393

ISBN : 979-10-300-0058-0

ISSN : 0007-4640

Référence électronique

Jacques Issorel, «Bernard Sicot, Djelfa 41-43. Un camp d'internement en Algérie (histoire, témoignages, littérature) », Bulletin hispanique [En ligne], 118-1 | 2016, mis en ligne le 15 juillet 2016, consulté le 23 septembre 2020. URL : http://journals.openedition.org/bulletinhispanique/4450 ; DOI : https://doi.org/ 10.4000/bulletinhispanique.4450

Ce document a été généré automatiquement le 23 septembre 2020

Tous droits réservés 


\section{Bernard Sicot, Djelfa 41-43. Un camp d'internement en Algérie (histoire, témoignages, littérature)}

Riveneuve, Paris, 2015

Jacques Issorel

\section{RÉFÉRENCE}

Bernard Sicot, Djelfa 41-43. Un camp d'internement en Algérie (histoire, témoignages, littérature), préface de Christian Phéline, Paris, Riveneuve, 2015, 442 p., 10 tableaux, 9 cartes et documents, 41 photographies h.t.

1 Le nom de Djelfa est à jamais associé à celui d'un écrivain - poète, romancier, dramaturge - qui « occupe maintenant une place de premier plan dans la littérature espagnole du XXe siècle»: Max Aub (p. 246). Son recueil poétique, Diario de Djelfa, d'abord publié au Mexique (1944 et 1970), puis en Espagne (1998), en France dans une édition bilingue avec introduction et notes de Bernard Sicot (2009), enfin de nouveau en Espagne dans une édition de ce même auteur (Visor, "Colección Visor de Poesía ", 2015), a révélé au monde l'horreur quotidienne du camp d'internement de Djelfa, institué en mars 1941 par le régime de Vichy pour y tenir enfermés jusqu'en 1943 « des meneurs extrémistes irréductibles » (p. 18). Dénoncé et arrêté à Paris en 1940, comme juif et communiste, incarcéré par deux fois au camp du Vernet d'Ariège, lui aussi de sinistre mémoire, Max Aub (1902-1973) séjourna à Djelfa du 28 novembre 1941 au 18 mai 1942. Quand il put enfin en sortir, il s'exila au Mexique.

Dès 2006, et surtout pour préparer son édition du Diario, Bernard Sicot avait réuni une très importante documentation autour de Max Aub et du camp algérien où celui-ci demeura six longs mois en compagnie de 476 Espagnols et de 667 hommes de diverses nationalités (Russes et Polonais en majorité), parmi lesquels nombre d'ex-brigadistes. Depuis 2009, il n'a cessé de poursuivre ce travail de recherche à la fois sur le camp et 
sur l'œuvre du poète. Il nous en offre le résultat dans le présent ouvrage que, sans abuser des mots, on ne peut que qualifier d'exhaustif. Celui-ci se compose d'une introduction sur «L'internement en Algérie » (p. 13-41), puis de deux grandes parties : I. « Le camp de Djelfa : mars 41-mai 43 » (p. 43-192) et II. «Écrire à Djelfa » (p. 193-270), suivies de « Conclusions ». Deux annexes complètent l'ouvrage. La première recueille 12 documents (" Témoignages et rapports », p. 279-389), dont 9 sont inédits et 3 inédits en français. Le second réunit 6 poèmes du Diario de Djelfa, traduits en français, extraits de l'édition bilingue de 2009 (p. 391-405).

Djelfa, comme l'explique l'auteur, est un camp de la troisième génération. La première répondit à l'urgence créée par l'arrivée en Afrique du Nord de 10 à 12000 réfugiés républicains espagnols fuyant le franquisme en mars 1939.6500 environ débarquèrent en Algérie. D'abord parqués sur les quais d'Oran ou dans des camps montés à la hâte, ils furent, au bout de quelques mois, répartis dans divers camps, comme ceux d'Orléansville et de Boghari, où, malgré l'inconfort des baraquements, hommes, femmes et enfants furent humainement traités. D'un ordre tout à fait différent était la troisième génération de camps, dont le but était d'éloigner de la métropole et d'isoler les hommes (seulement les hommes) que le gouvernement de Vichy considérait comme « indésirables dangereux " (p. 26). Les plus inhumains de ces camps, appelés «Centres de séjour surveillé », furent ceux d'Hadjerat M' Guil, de Djenien Bou Rezg et de Djelfa.

De ce dernier, situé à $300 \mathrm{~km}$ au sud d'Alger, d'abord constitué de tentes marabout dressées sur un quadrilatère de 300 mètres sur 100, puis de baraquements insalubres et non chauffés en hiver, il ne reste aujourd'hui à peu près aucune trace, si ce n'est, à un kilomètre de là, dans la ville de Djelfa, le fort Caffarelli, qui servait de cachot. Grâce à des photos saisissantes, prises malgré les interdictions et les sanctions par des internés, on a une idée de ce que fut ce camp établi à 1200 mètres d'altitude, sur une steppe balayée en permanence par des vents glacials en hiver, brûlants en été. Mais c'est surtout grâce aux documents retrouvés et réunis par Bernard Sicot que l'on connaît en détail ce qu'était la vie quotidienne des internés. Ces documents sont de plusieurs sortes et parfois contradictoires. Ainsi André Jean-Faure, envoyé par Vichy en mission d'inspection, au terme d'une longue suite d'«ellipses», de "non-dits», d'« euphémismes » et de "métaphores périphrastiques» (p. 106), conclut que « le camp de Djelfa, bien dirigé, bien tenu, offre un ensemble qui échappe à toute critique sérieuse » (p. 333). Les députés communistes Henri Martel et Antoine Desmusois, eux aussi en mission d'inspection, mais en mars 1943 (c'est-à-dire après le débarquement des Alliés en Afrique du Nord), les anciens internés que furent le médecin russe Alexandre Roubakine, Élie Gozlan, David Kleinman, Paul Zolberg et Max Aub lui-même, auteur de cinq textes en prose écrits au Mexique dès 1942, lus par lui lors d'« Assemblées contre la terreur nazie-fasciste» (Annexe I, p. 279-389), concordent pour dénoncer les souffrances physiques et morales infligées gratuitement aux internés. Dans ces textes souvent bouleversants sont révélées les cruautés du commandant du camp, Jules Caboche et de l'adjudant Jean Gravelle, qui, entre autres brutalités et humiliations, frappaient les internés au visage à coups de cravache.

5 Avec 1200 à 1500 calories par jour, les rations alimentaires (soupes claires, pas de viande ni de fruits) étaient très insuffisantes, l'hygiène inexistante, les soins médicaux tout autant. Les internés qui en avaient les moyens se procuraient un peu de nourriture en pratiquant le troc avec leurs gardiens algériens, mais c'était souvent au prix de très lourdes sanctions, en particulier l'incarcération au fort Caffarelli ou, tout aussi terrible, 
dans le camp spécial, «périmètre réduit, interne au camp [avec] une dizaine de tentes entourées de barbelés » (p. 100). Les reclus y vivaient vêtus de haillons, sans hygiène et ne comptaient que sur la solidarité de leurs camarades pour ne pas mourir d'inanition (p. 362).

6 Le commandant Caboche poussait le cynisme jusqu'à offrir aux internés volontaires la possibilité d'obtenir 100 à 150 grammes de pain supplémentaire par jour, en échange d'un travail, soit à l'extérieur du camp (mais c'était Caboche qui percevait et conservait les 20 francs de leur salaire quotidien), soit dans un des nombreux ateliers organisés et supervisés par le commandant en personne, assisté de quelques internés " collaborateurs »: briqueterie, tuilerie, tannerie, forge, menuiserie. Les internés fabriquaient aussi du plâtre, de la chaux et tissaient le sparte pour confectionner des espadrilles et des couffins. Le produit de leur travail était vendu au seul bénéfice du commandant et de quelques complices : «Un an après sa création, écrit Bernard Sicot, ce qui ne devait être qu'un "centre de séjour surveillé" où il était bon de ne pas laisser les internés inactifs s'était bel et bien reconverti en camp de travail très lucratif pour certains" (p.144). Étaient cependant exclus de ces travaux, et donc privés du supplément de pain et condamnés à l'ennui, les juifs et les ex-brigadistes.

7 La deuxième partie du livre, «Écrire à Djelfa », nous parle des écrits de trois internés : Paul Zolberg, juif polonais communiste, Antonio Atarés, anarchiste espagnol et Max Aub. Après avoir fait preuve d'historien, l'auteur se livre maintenant avec brio à un exercice d'exégèse et de critique littéraire. «Écrire au camp était toujours un acte de résistance ", lit-on sous sa plume au sujet de Zolberg (p.193) et l'on voit ce dernier écrire «avec ardeur» (p.195) sur des cahiers d'écolier auxquels il donne le titre significatif d'" Aide- mémoire ", sans jamais «faire référence à aucun destinataire, ni à d'éventuels lecteurs » (p. 196) : il écrit pour ne pas oublier. Si ses « dons de conteur [...] lui permettent de rendre compte de l'« "intimité" quotidienne du baraquement et d'y faire pénétrer son lecteur» (p. 199), il sait aussi observer les Arabes, " presque à poil et nu-pieds » et dénonce, indigné, les méfaits d'un siècle de colonisation: "Ils sont presque sauvages encore, écrit-il, et vivent comme des bêtes et des animaux! Se laissent mener et conduire comme sous le temps de servage et exploiter à outrance par colons et Européens en général» (p. 207). Nous verrons plus bas le regard que portait Max Aub sur cette même misère des Algériens de l'époque.

8 C'est un titre volontairement paradoxal que donne Bernard Sicot aux 24 pages consacrées à Antonio Atarés («Ce qu'Atarés écrivait»), qui échangea avec la philosophe Simone Weil une brève mais riche correspondance entre 1941 et 1942, puisque ses lettres «à l'exception d'une seule, non parvenue à sa destinataire, sont introuvables » (p. 211). C'est donc à une recherche des mots d'Atarés à travers leur reflet dans les lettres de la jeune philosophe, quant à elles bien conservées et publiées, que s'attache ici Bernard Sicot. On découvre avec lui un " anarchiste illettré mais cultivé » (p. 219), qui connaît Platon, Eschyle et saint Jean de la Croix, poète lui-même, dont « la hauteur des sentiments est indiscutable » (p. 224). On y apprend aussi que, malgré ses efforts et ses démarches, Simone Weil ne parvint pas à faire libérer le jeune Antonio, dont elle admirait le stoïcisme, allant même, dans une lettre adressée à un religieux de ses amis, jusqu'à voir en lui un saint laïque : « [Le] paysan espagnol, écrivait-elle, avec qui je suis en correspondance et que je ne crois pas éloigné de la sainteté » (p. 232).

Il était normal qu'à Max Aub, qui, selon l'expression baudelairienne, de la boue sut faire de l'or, fût consacré un nombre de pages plus important qu'à Zolberg et à Atarés. Dans 
un texte retrouvé dans les archives du poète, Aub justifie le choix du vers pour écrire son Journal : « Lorsque, au camp, j'ai essayé d'écrire le plus simplement ce qui se passait, c'est en vers que cela m'est venu. Le vers est ce qu'il y a de plus nu» (p. 257). Et il ajoute un peu plus loin : «Les choses telles qu'elles furent, sans allégories, sans images pour ne pas donner lieu à des interprétations personnelles" (ibid.). Ces lignes sont essentielles, comme l'explique l'auteur, pour pleinement apprécier la poétique et l'esthétique de Diario de Djelfa. Aub en appelle même à l'autorité de Fray Luis de León (" para que el estilo del decir se asemejase al sentir, y las palabras y las cosas fuesen conformes »), rejetant du même coup, comme impropre à sa volonté d'être, outre un créateur, un témoin, la conception becquérienne de la poésie. Aussi Bernard Sicot insiste-t-il sur «le caractère bi-fonctionnel du Journal », témoignage d'une expérience atroce, mais également œuvre de création, afin que, dépassant le «stade du document », celle-ci s'inscrive dans la " pérennité » (p. 252).

Le désir constant de Max Aub de porter témoignage en son nom et au nom de tous ses compagnons, morts de faim, de froid, de maladie, à Djelfa, ou rescapés, induit un vocabulaire d'une crudité et d'une violence auxquelles la poésie ne nous a guère habitués. Ces vers n'auraient pas pu être de nature différente. Écrits dans la souffrance, inspirés par la colère et l'humiliation, ils crient avec la force de l'espoir, le désir de voir un jour les tortionnaires punis. Leurs noms sont cités, comme celui de l'adjudant Gravelle dans le « Romance de Gravelle »: « ¿Cómo quieres que te olvide, / tú, Gravela, hijo de puta... » (p. 403 ; p. 238 dans l'édition bilingue).

11 Ce déchaînement poétique est pourtant loin d'être la note unique de Diario de Djelfa. Plusieurs poèmes sont écrits dans un style beaucoup plus apaisé, ainsi ceux que Max Aub compose pour ses filles: " Noches », "Cancionerillo africano » et " Amaneceres », respectivement dédiés à Elena, Mimín et Carmen. Dans ces poèmes écrits en touches rapides, le poète atteint l'excellence. Pourtant, au sein même des évocations lyriques du matin, du printemps, ou bien dans la fantaisie débridée de «Moda niña » (première partie de "Noches»), soudain fait irruption un "oscuro enredo" et on lit dans le poème suivant, "Cancionerillo africano »: " Aquí todo es violento / .... / todo ronco, bronco, duro " (ibid., p. 186). Même dans un poème comme "Mora " (ibid., p. 226), où l'on voit passer d'un pas rapide et infiniment gracieux une jeune Mauresque qui, vraisemblablement se sentant regardée par le poète, lui jette un regard furtif («Una morilla / anda cernidilla, / blanco garbo, / blanca gracia, / blancos pliegues / y repliegues, / blanca almalafa »), la souffrance du prisonnier, un instant oubliée, envahit de nouveau tout l'espace poétique: «El preso que la ve / queda más preso », et le poème s'achève, comme il avait commencé, sur la vision d'un paysage désespérément hostile. Des poèmes comme celui-ci aussi bien que ceux où le poète pleure l'« España muerta, / la que fue » («Salmo CXXXVII », ibid., p. 202), ceux où, à travers le paysage de Djelfa, il croit retrouver les paysages secs d’Espagne ( ¿Dónde estás España? Donde sea te veo ", ibid., p. 160), ceux encore où il appelle son pays au secours (" Ven a salvarnos, / ¡Oh España! Haznos tornar ", ibid., p. 208) doivent être lus à la lumière de ce qu'écrit Max Aub dans son prologue : « [A mis poesías] les debo quizá la vida porque al parirlas cobraba fuerza para resistir el día siguiente » (ibid., p. 58). Cette nourriture spirituelle, le poète la partageait avec ses compagnons d'infortune le soir sous les tentes: "Solíamos leerlos, hambreados y lívidos, a la luz de una mariposa cuidadosamente resguardada, bajo las tiendas de campañas, ocultándola de la crueldad imbécil de unos guardianes ciegos » (ibid.). Bernard Sicot appelle avec beaucoup de bonheur ces séances de lecture nocturnes des "cènes festives ", ajoutant que "dans ces célébrations des 
catacombes, autour de la langue espagnole des vers d'Aub, les prisonniers se rassasiaient d'une nourriture grâce à laquelle se fortifiait ou se recomposait l'esprit communautaire" (ibid., p.37). Il insiste aussi sur la tonalité épique du recueil : les anciens combattants de la guerre d'Espagne, « héros [tout aussi] loqueteux » que leurs gardiens algériens, sont comme ces derniers, appelés à « des combats libérateurs à venir » (p. 259) : « Parece que los dos / tengamos igual guarda / y nos llegará el día / de la misma almenara ", traduit ainsi dans l'édition bilingue : «Les uns les autres, on dirait, / avons les mêmes gardiens; / contre eux le même signal / un jour nous parviendra bien » (p. 92-93).

Riche de 41 photos en couleurs et en noir et blanc, de témoignages précis et poignants, ce fort volume témoigne de la volonté de son auteur de tout dire sur le grand scandale que fut le camp de Djelfa, sur la souffrance et la dignité des internés ${ }^{1}$. Il se présente comme un modèle méthodologique pour de futurs chercheurs, car, comme cela apparaît dans le tableau détaillé de la p. 27, il y eut d'autres camps de séjour surveillé en Algérie. C'est aussi à un devoir de mémoire que Bernard Sicot appelle les Algériens dans une de ses conclusions (p. 276-277). À la page suivante, il cite plusieurs œuvres, traduites ou pas en français, qui appartiennent, comme le Diario, à la littérature des camps. Aux dix titres cités on pourrait ajouter Arena y viento. Romances del refugiado [1939-1940] (1949) et Un «rojillo» en el Sur de Francia seguido de Arena y viento. Segundo libro (éd. bilingue, 2009) de Manuel Pérez Valiente, sous les signatures respectivement de Juan de Pena et de Manolo Valiente.

\section{NOTES}

1. Cette série de photos peut être complétée avec l'article de B. Sicot: « Djelfa 41-43. Un camp d'internement en Algérie : addenda iconographique ", Cahiers de civilisation espagnole contemporaine, $\mathrm{n}^{\circ}$ 14, printemps 2015, http://ccec.revues.org/5693. Outre des plans et des photos du camp, on y voit celle du commandant Caboche, cravache à la main.

\section{AUTEURS}

JACQUES ISSOREL

Université de Perpignan 